\title{
Hard-on-Hard Bearings Are Associated With Increased Noise Generation in Young Patients Undergoing Hip Arthroplasty
}

\author{
Denis Nam MD, MSc, Toby Barrack BA, Staci R. Johnson MEd, \\ Ryan M. Nunley MD, Robert L. Barrack MD
}

Published online: 24 February 2016

(C) The Association of Bone and Joint Surgeons (B) 2016

\begin{abstract}
Background Patient-perceived noise from prostheses after total hip arthroplasty (THA) does occur, yet questions remain including the overall frequency of this finding, demographic and prosthesis-related factors, and the association of noise generation with patient-reported outcomes. Questions/purposes The purposes of this study were (1) to determine the frequency with which patients report noise coming from the hip after THA; (2) to identify patient and prosthesis-related factors associated with noise generation;
\end{abstract}

The institution of the authors has received, during the study period, funding from Smith \& Nephew Inc (Memphis, TN, USA) in support of this study (RMN).

All ICMJE Conflict of Interest Forms for authors and Clinical Orthopaedics and Related Research ${ }^{\mathbb{R}}$ editors and board members are on file with the publication and can be viewed on request.

Clinical Orthopaedics and Related Research ${ }^{\mathbb{R}}$ neither advocates nor endorses the use of any treatment, drug, or device. Readers are encouraged to always seek additional information, including FDAapproval status, of any drug or device prior to clinical use.

Each author certifies that his or her institution approved the human protocol for this investigation, that all investigations were conducted in conformity with ethical principles of research, and that informed consent for participation in the study was obtained.

Electronic supplementary material The online version of this article (doi:10.1007/s11999-016-4759-6) contains supplementary material, which is available to authorized users.

D. Nam, T. Barrack, S. R. Johnson, R. M. Nunley, R. L. Barrack Department of Orthopaedic Surgery, Washington University School of Medicine/Barnes-Jewish Hospital, St Louis, MO, USA

D. Nam $(\bowtie)$

Washington University Orthopedics, Barnes Jewish Hospital, 660 S Euclid Avenue, Campus Box 8233, St Louis, MO 63110, USA

e-mail: namd@wudosis.wustl.edu and (3) to ascertain if noise generation is associated with pain or functional impairment after THA.

Methods A five-center study was designed to quantify the degree of residual symptoms and functional deficits in patients undergoing THA. Three centers were academic practices, whereas two centers were private practices that provided training programs for orthopaedic residents and fellows. Each contributing surgeon was fellowship-trained and specialized in joint replacement. Inclusion criteria for this study were (1) men between 18 and 60 years old and women between 18 and 55 years old; (2) patients requiring primary hip surgery as a result of noninflammatory arthritis such as osteoarthritis, traumatic arthritis, or avascular necrosis; (3) a UCLA activity score of 6 or more before they were limited by pain; and (4) patients who had undergone a primary THA within 1 to 4 years before the start of the study and had a minimum of 1 year of clinical followup. Attempts were made to contact all identified patients meeting these inclusion criteria. Data were collected by an independent, third-party survey center blinded to the implant design and bearing surface used who administered questionnaires about residual symptoms, function, and pre- and postoperative activity levels using previously published survey instruments. Patients were specifically queried regarding perceived noise from their THA. We retrospectively identified 1242 eligible patients. Of the 1242 patients, 105 were found to have exclusions during the screening section of the questionnaire: postoperative infection (six THAs), fracture (two), dislocation (seven), or revision (17); limited activity level because of an operation on the opposite hip (34); and premorbid UCLA score of less than 6 (39). In addition, 128 individuals refused to participate, 156 were never available, 108 were not found as a result of a bad address/phone number, 48 were contacted but did not complete the interview, nine 
had died, and six had a language barrier. This left 682 of the 1137 eligible patients with completed surveys $(60 \%$ response rate). The mean age was $50 \pm 8$ years at the time of surgery with $63 \%$ being men, and they were contacted at a mean of $3 \pm 1$ years postoperatively. Bearing surfaces (femoral head-acetabular liner) included 210 (31\%) metalon-metal, 144 (21\%) ceramic-on-ceramic, 142 (21\%) ceramic-on-polyethylene, 141 (21\%) cobalt-chromium-onpolyethylene, and 44 (6\%) oxidized zirconium-onpolyethylene. Differences in baseline demographic variables were accounted for using multiple logistic regression statistical analyses. Pearson's correlation coefficients were used to determine the association of noise generation with residual symptoms.

Results Overall, 9\% (61 of 682; 95\% confidence interval [CI], 7-11) of young patients undergoing primary THA reported noise generation. Females (12\% [30 of 251 patients]) were noted to have an increased likelihood of reporting noise versus males ( $7 \%$ [30 of 431 patients]; odds ratio, 1.8; 95\% CI, 1.1-3.1; $\mathrm{p}=0.03$ ). After controlling for potential confounding variables including female sex and length of followup, patients receiving a ceramic-on-ceramic or metal-on-metal bearing surface (14\% [50 of 355]) reported an increased frequency of grinding, popping, and clicking in the 30 days before survey administration versus those receiving a polyethylene liner with a ceramic, oxidized zirconium, or cobalt-chromium femoral head $(3 \%$ [10 of 327 patients]; odds ratio, 5.6; 95\% CI, 2.7-11.5; $\mathrm{p}<$ $0.001)$. Noise generation was associated with increased pain $(r=0.23, p<0.001)$ and stiffness $(r=0.22, p<0.001)$ after THA.

Conclusions When interviewed by an independent third party, patients receiving a metal-on-metal or ceramic-onceramic bearing reported a higher frequency of noise generation versus patients receiving a polyethylene liner after THA. Young patients undergoing THA should be counseled that noise generation could be associated with increased pain after THA.

Level of Evidence Level III, therapeutic study.

\section{Introduction}

Because THA has demonstrated lasting clinical success [20], it has been offered to younger and more active patients $[17,18]$. However, concern about the longevity of standard polyethylene bearings led to increased use of hard-on-hard bearings. When introduced into the US market, both metal-on-metal (MoM) and ceramic-on-ceramic $(\mathrm{CoC})$ bearings were met with significant enthusiasm [11, 13 , 27, 33]. By 2006, approximately $35 \%$ and $14 \%$ of THAs were implanted with a MoM or $\mathrm{CoC}$ bearing, respectively [6]. However, use of hard-on-hard bearings has declined substantially since then because of concerns for metal toxicity in the case of MoM [19, 25, 33] and breakage in the case of $\mathrm{CoC}[1,15,22,23]$.

In addition, published reports began to note the phenomenon of noise associated with hard-on-hard bearings $[1,2,8,14,24]$. However, prior reports have been limited by the potential for observer bias, the variability in which noise generation was assessed, and a lack of correlation with patient-reported outcomes. Thus, questions remain regarding the true frequency of patient-perceived noise generation after THA with metal-on-polyethylene (MoP), $\mathrm{MoM}$, and $\mathrm{CoC}$ bearings along with its correlation with patient-reported outcomes.

We therefore sought to (1) determine the frequency with which patients report noise coming from the hip after THA; (2) identify patient and prosthesis-related factors associated with noise generation; and (3) ascertain if noise generation is associated with pain or functional impairment after THA in young patients undergoing THA. We specifically sought to evaluate these variables in young patients because MoM and $\mathrm{CoC}$ bearings were commonly used in this population.

\section{Patients and Methods}

Five total joint centers (Washington University School of Medicine, St Louis, MO, USA; Rush University Medical Center, Chicago, IL, USA; Anderson Orthopaedic Clinic, Arlington, VA, USA; Joint Replacement Surgeons, Mooresville, IN, USA; Rothman Institute of Orthopaedics, Philadelphia, PA, USA) and an independent third-party survey center (University of Wisconsin Survey Center [UWSC], Madison, WI, USA) participated. Three centers were academic practices, whereas two centers were private practices that provided training programs for orthopaedic residents and fellows. Each center had an active joint replacement registry, and all surgeons were fellowshiptrained performing more than 200 THAs per year; each contributed patients meeting the inclusion criteria. Each center had a particular interest and experience with a specific bearing couple and was beyond the learning curve associated with its use. Before initiation of the study, institutional review board approval was obtained at the Washington University School of Medicine to serve as the coordinating center, and each participating center obtained approval from its institutional review board.

Inclusion criteria for this study were (1) men between 18 and 60 years old and women between 18 and 55 years old; (2) patients requiring primary hip surgery as a result of noninflammatory arthritis (degenerative joint disease) such as osteoarthritis, traumatic arthritis, or avascular necrosis; and (3) a UCLA activity score [35] of 6 or more before they were limited by hip pain. Age limits were instituted 
because MoM and CoC bearings are typically selected for younger patients. We excluded (1) subjects with a history of infection or sepsis in the hip, fracture, dislocation, or revision to the operated hip; and (2) patients with extensive medical comorbidities including renal failure, coronary artery disease, liver disease, sickle cell disease, respiratory disease, cancer, etc, that would limit their activity level. These patients were excluded to compare well-performing implants. Investigators queried their total joint registries and compiled a list of patients meeting the inclusion criteria who had undergone a primary THA within 1 to 4 years of the start of the study and had a minimum of 1 year of clinical followup. Each center was able to produce a list of patients who met the inclusion criteria including age, date of surgery, and complete contact information for each patient.

We retrospectively identified 1242 eligible patients between January 2005 and July 2007. Of the 1242 patients, 105 were found to have exclusions during the screening section of the questionnaire: postoperative infection (six THAs), fracture (two), dislocation (seven), or revision (17); limited activity level because of an operation on the opposite hip (34); and premorbid UCLA score of less than 6 (39). In addition, 128 individuals refused to participate, 156 were never available, 108 were not found as a result of a bad address/phone number, 48 were contacted but did not complete the interview, nine had died, and six had a language barrier. This left 682 of the 1137 eligible patients with completed surveys. The final study group was $63 \%$ male with a mean age of $50 \pm 8$ years at the time of surgery and they were contacted at a mean of $3 \pm 1$ years postoperatively.

All patients receiving THA had cementless stems with an advanced bearing surface: MoM (210 patients; 31\%), CoC (144 patients; 21\%), or highly crosslinked polyethylene articulating with femoral heads of cobaltchromium (141 patients; 21\%), ceramic (142 patients; $21 \%$ ), or oxidized zirconium (44 patients; $6 \%$; Oxinium $^{\mathrm{TM}}$; Smith \& Nephew, Inc, Memphis, TN, USA). Oxidized zirconium femoral heads were always used with a highly crosslinked polyethylene articulation for the acetabular bearing. The bearing surface used was at each surgeon's discretion. At one site, all young patients during this study period received a MoM bearing surface. At a second site, all young patients during this study period received a $\mathrm{CoC}$ bearing surface. The three remaining sites used highly crosslinked polyethylene with a cobalt-chromium, ceramic, or oxidized zirconium femoral head based on surgeon preference and the manufacturer of the implant design they used for THA. The selection of femoral head size was also at the surgeon's discretion with femoral head sizes classified as standard $(\leq 32 \mathrm{~mm} ; \mathrm{n}=359)$ and big head $(>32$ $\mathrm{mm} ; \mathrm{n}=323$ ).
We used a previously described survey [3] reporting specific data regarding function and residual symptoms 1 to 4 years after THA. The survey was designed by the UWSC in conjunction with Washington University and questions were adapted from commonly used orthopaedic scores including the Hip Disability and Osteoarthritis Outcome Score [26], the Modified Harris hip score [9, 16], the UCLA activity score [35], and the Patient-Specific Index [34]. To eliminate observer bias, the UWSC, an independent, blinded third party, performed all data collection. The UWSC was selected for their expertise in collecting health data for state and federal agencies [10, 28] and for having no affiliation with any of the participating centers. Each center reviewed its joint registry to identify patients meeting eligibility criteria and provided the list to the coordinating center at Washington University where they were compiled into a master database. The implant details were removed and only the contact information and date and side of surgery were provided to the UWSC to ensure anonymous, blinded administration of the survey. The coordinating center maintained a comprehensive list of implant details to decode by implant type after interviews were complete, before data analysis. Patients received advance notification letters approximately 1 week before they were contacted by the survey center. Interviewers obtained verbal consent, a screening section ensured patients met the inclusion criteria, and the full questionnaire was administered to those patients who both provided verbal consent and were determined to be eligible and capable to participate. All interviews were conducted in English. The telephone survey protocol included 25 telephone call attempts per patient. The final data were sent from the UWSC through a secure website in SPSS format (Version 16.0; SPSS Inc, Chicago, IL, USA).

This report focuses on the specific questions of the survey focusing on noise generation (popping, clicking, grinding, or other noises) and their association with perceived pain, limp, and stiffness. The entire survey questionnaire consisted of approximately 50 questions that would potentially vary based on the use of skip-logic survey administration using the Computer-Assisted Survey Execution System (developed at University of California Berkeley, Berkeley, CA, USA). Twenty to 25 minutes was required to complete the survey, because questions regarding functional activities, patient satisfaction, return to work, and sexual function were also administered. Questions regarding noise generation were present in the first section of the questionnaire. Patients were specifically asked "In the last 30 days, how often did you experience grinding or popping or hear clicking or other noises from your (left/right) hip: never, rarely, sometimes, often, extremely often?" The purpose of this question was to elucidate if patients perceived any type of noise coming 
from their hip. Patients were queried about residual symptoms in their hip in the last 30 days before survey administration (Appendix 1 [Supplemental materials are available with the online version of $C O R R^{\circledR}$.]). Questions regarding symptoms and function had five response categories as described by Likert [21]. The responses were grouped into two categories of "never/rarely" and "sometimes/often/extremely often" for comparison during data analysis based on the methodology described by Bourne et al. [5]. Missing responses were excluded from the statistical analysis.

Bearing surface types were classified into two categories: "polyethylene" and "hard-on-hard." Because the frequency of noise generation was virtually identical in patients receiving a highly crosslinked polyethylene with femoral heads of cobalt-chromium, ceramic, or oxidized zirconium, these patients were grouped together to form the "polyethylene" cohort. Similarly, patients receiving MoM and $\mathrm{CoC}$ bearings were grouped together to form the "hard-onhard" cohort. This left 355 patients in the hard-on-hard and 327 patients in the polyethylene cohort. There was a greater percentage of males in the hard-on-hard versus polyethylene cohort (67\% versus 59\%; $\mathrm{p}=0.04)$, and average length of followup was greater in the hard-on-hard cohort $(2.6 \pm 0.7$ versus $2.3 \pm 0.7$ years; $\mathrm{p}<0.001$; Table 1 ).

We used descriptive statistics to present categorical data with frequency and percentage. Chi-square analyses and Fisher's exact tests were used to compare categorical data. Multivariate analysis was conducted to examine the reporting of noise generation among bearing surfaces after adjusting for age, sex, minority status ("minority" considered black, Hispanic, or nonwhite), premorbid UCLA scores, and length of followup. Pearson's correlation coefficients were performed to determine the association of noise generation with residual symptoms. An independent statistician (ML) not involved in patient care performed all analyses using SAS 9.2 software (Cary, NC, USA). A p value $<0.05$ was considered statistically significant.

\section{Results}

Overall, $9 \%$ (61 of $682 ; 95 \%$ confidence interval [CI], 711) of young patients undergoing primary THA reported noise generation. Female sex (12\% [30 of 251 patients]) was associated with an increased reporting of noise generation versus male sex (7\% [30 of 431 patients]; odds ratio, $1.8 ; 95 \% \mathrm{CI}, 1.1-3.1 ; \mathrm{p}=0.03)$. We found no association between age $\left(\chi^{2}[\mathrm{df}=3]=6.8 ; \mathrm{p}=0.08\right)$, primary diagnosis $\left(\chi^{2}[\mathrm{df}=3]=2.6 ; \mathrm{p}=0.5\right)$, minority status (odds ratio $[\mathrm{OR}], 0.4 ; 95 \% \mathrm{CI}, 0.1-2.0 ; \mathrm{p}=0.3)$, and preoperative UCLA score $\left(\chi^{2}[\mathrm{df}=4]=7.1 ; \mathrm{p}=0.1\right)$ and the likelihood a patient would report noise generation.
Patients receiving a hard-on-hard bearing were more likely to report noise generation (popping, clicking, or grinding) than patients in the polyethylene cohort. Accounting for differences in sex and length of followup, patients receiving a hard-on-hard bearing surface (14\% [50 of 355]) were more likely to report noise generation in the 30 days before survey administration versus those receiving a polyethylene liner with a ceramic, oxidized zirconium or cobalt-chrome femoral head (3\% [10 of 327 patients], odds ratio, 5.6; 95\% CI, 2.7-11.5; $\mathrm{p}<0.001)$. . There was no difference in the reporting of noise generation based on femoral head size (7\% [26 of 359] for head size $\leq 32 \mathrm{~mm}$ versus $11 \%$ [34 of 323 ] for head size $\geq 36 \mathrm{~mm}$; odds ratio, $0.7 ; 95 \%$ CI, 0.4-1.1; $\mathrm{p}=0.1$ ).

Patients reporting noise generation in the hard-on-hard cohort were more likely to report the presence of pain and stiffness in the hip and the presence of a limp (Table 2). Patients with ongoing pain in the hip are more likely to report noise generation (23\% [28 of 123] versus $10 \%$ [22 of 230], odd ratio, 2.8; 95\% CI, 1.5-5.1; p = 0.007). Similarly, patients who reported the presence of a limp are more likely to report noise generation (21\% [21 of 98] versus $11 \%$ [28 of 255 ], odds ratio, $2.2 ; 95 \% \mathrm{CI}, 1.2-4.1 ; \mathrm{p}=$ $0.01)$.

Although patients reporting noise generation in the polyethylene cohort were rare, they were more likely to report the presence of pain in the hip (Table 3). Patients with ongoing pain in the hip are more likely to report noise generation $(6 \%$ [seven of 126] versus $1 \%$ [three of 201], odds ratio, 3.9; 95\% CI, 1.0-15.3; $\mathrm{p}=0.04)$.

In both the hard-on-hard and polyethylene cohorts, positive correlations were noted between the reporting of noise generation and residual postoperative symptoms. In the hard-on-hard cohort, noise generation was associated with increased pain $(\mathrm{r}=0.314, \mathrm{p}<0.001)$ and stiffness $(\mathrm{r}=$ $0.309, \mathrm{p}<0.001)$. In the polyethylene cohort, noise generation was associated with increased pain $(r=0.273, \mathrm{p}<$ $0.0001)$.

\section{Discussion}

Patient-perceived noise generation is a recognized symptom after THA, yet prior reports have been discordant regarding both its frequency and potential impact on patient-reported outcomes [29, 30]. Although prior studies have focused on noise generation, especially after implantation of $\mathrm{CoC}$ bearings, they have been limited by the potential for observer bias diminishing both their true frequency and their potential impact on patient symptoms. Prior investigations have been limited because they often focus solely on the presence of "squeaking" rather than noise generation in general. Furthermore, correlation of the 
presence of noise with overall patient-perceived outcome has not been established. Thus, the purposes of this study were to determine the frequency, potential demographic and prosthesis-related factors, and potential association of patient-perceived noise generation with pain or functional

Table 1. Demographics in the hard-on-hard and polyethylene cohorts

\begin{tabular}{|c|c|c|c|}
\hline Patient characteristics & $\begin{array}{l}\text { Hard-on-hard } \\
\text { bearing }\end{array}$ & Polyethylene & $\mathrm{p}$ value \\
\hline Sex & & & 0.0444 \\
\hline Female & $118(33 \%)$ & $133(41 \%)$ & \\
\hline Male & $237(67 \%)$ & $194(59 \%)$ & \\
\hline Age category (years) & & & 0.3404 \\
\hline$<40$ & $35(10 \%)$ & $35(11 \%)$ & \\
\hline $40-49$ & $123(35 \%)$ & $100(31 \%)$ & \\
\hline $50-55$ & $154(43 \%)$ & $138(42 \%)$ & \\
\hline $56-60$ & $43(12 \%)$ & $54(17 \%)$ & \\
\hline Primary diagnosis & & & 0.4504 \\
\hline Osteoarthritis & $313(88 \%)$ & $284(87 \%)$ & \\
\hline Avascular necrosis & $22(6 \%)$ & $27(8 \%)$ & \\
\hline Hip dysplasia & $18(5 \%)$ & $12(4 \%)$ & \\
\hline Other & $2(1 \%)$ & $4(1 \%)$ & \\
\hline Race & & & 0.3831 \\
\hline Black & $22(6 \%)$ & $29(9 \%)$ & \\
\hline White & $319(90 \%)$ & $282(86 \%)$ & \\
\hline Other & $14(4 \%)$ & $14(4 \%)$ & \\
\hline Presymptomatic UCLA score & & & 0.1320 \\
\hline 6 & $110(31 \%)$ & $109(33 \%)$ & \\
\hline 7 & $27(8 \%)$ & $31(9 \%)$ & \\
\hline 8 & $38(11 \%)$ & $50(15 \%)$ & \\
\hline 9 & $47(13 \%)$ & $39(12 \%)$ & \\
\hline 10 & $133(37 \%)$ & $97(30 \%)$ & \\
\hline \multirow[t]{2}{*}{ Length of followup (years) } & & & $<0.001$ \\
\hline & $3 \pm 1$ & $2 \pm 1$ & \\
\hline
\end{tabular}

impairment in young patients undergoing THA. To minimize concerns regarding selection bias, a multicenter study was designed to collect data from a large group of young patients. To eliminate observer bias, an independent, blinded third party performed all data collection. We found patients receiving a hard-on-hard bearing (MoM or $\mathrm{CoC}$ ) were more likely to report noise generation than were patients receiving a highly crosslinked polyethylene liner with femoral heads of cobalt-chromium, ceramic, or oxidized zirconium. Reporting of noise generation was associated with increased pain after THA regardless of the bearing surface.

This study had several limitations that must be recognized before interpretation of our data. First, because this study was retrospective, we can only determine the presence of an association of noise generation with patient satisfaction and residual symptoms. Thus, we recognize that noise generation itself might not be the cause of limitations in patient function. Second, use of a retrospective survey method has the potential for recall bias, but we tried to limit the degree of bias by only including patients who received a THA within 1 to 4 years before the start of the study. However, because we only included patients with 1 year followup, it is possible that patients who do not have 1 year followup (and thus were excluded) or who had undergone a revision surgery may experience an even greater frequency of noise generation than we have reported. Thus, this study may represent a best-case analysis in terms of the frequency of noise generation, residual symptoms, and functional limitations. However, we believe that a strength of this investigation is the use of an independent, blinded third party to perform all data collection, thus limiting potential observer bias. Furthermore, to minimize concerns regarding selection bias, a multicenter study was designed to collect data from a large group of patients undergoing THA. Third, although the survey instrument has previously been reported and is adapted

Table 2. Noise generation and residual symptoms in the hard-on-hard cohort

\begin{tabular}{|c|c|c|c|}
\hline Residual symptom & Never/rarely hears noise & $\begin{array}{l}\text { Sometimes/often/extremely } \\
\text { often hears noise }\end{array}$ & $\mathrm{p}$ value \\
\hline Last 30 days felt pain in the hip & & & Odds ratio, $2.8 ; 95 \% \mathrm{CI}, 1.5-5.1 ; \mathrm{p}=0.007$ \\
\hline Yes & $95(77 \%, 95$ of 123$)$ & $28(23 \%, 28$ of 123$)$ & \\
\hline No & $208(90 \%, 208$ of 230$)$ & $22(10 \%, 22$ of 230$)$ & \\
\hline Last 30 days felt stiffness in the hip & & & Odds ratio, 3.6; 95\% CI, 1.9-6.8; $\mathrm{p}<0.001$ \\
\hline Never/rarely & $256(90 \%, 256$ of 286$)$ & $30(10 \%, 30$ of 286$)$ & \\
\hline Sometimes/often/extremely often & $48(71 \%, 48$ of 68$)$ & $20(29 \%, 20$ of 68$)$ & \\
\hline How often do you limp & & & Odds ratio, $2.2 ; 95 \% \mathrm{CI}, 1.2-4.1 ; \mathrm{p}=0.01$ \\
\hline Never/rarely & $227(89 \%, 227$ of 255$)$ & $28(11 \%, 28$ of 255$)$ & \\
\hline Sometimes/often/extremely often & $77(79 \%, 77$ of 98$)$ & $21(21 \%, 21$ of 98$)$ & \\
\hline
\end{tabular}

$\mathrm{CI}=$ confidence interval. 
Table 3. Noise generation and residual symptoms in the polyethylene cohort

\begin{tabular}{|c|c|c|c|}
\hline Residual symptom & $\begin{array}{l}\text { Never/rarely hears } \\
\text { noise }\end{array}$ & $\begin{array}{l}\text { Sometimes/often/extremely } \\
\text { often hears noise }\end{array}$ & $\mathrm{p}$ value \\
\hline Last 30 days felt pain in the hip & & & Odd ratio, $3.9 ; 95 \% \mathrm{CI}, 1.0-15.3 ; \mathrm{p}=0.04$ \\
\hline Yes & $119(94 \%, 119$ of 126$)$ & $7(6 \%, 7$ of 126$)$ & \\
\hline No & $198(99 \%, 198$ of 201$)$ & $3(1 \%, 3$ of 201$)$ & \\
\hline Last 30 days felt stiffness in the hip & & & Odds ratio, 2.6; 95\% CI, 0.7-9.6; $\mathrm{p}=0.13$ \\
\hline Never/rarely & $253(98 \%, 253$ of 259$)$ & $6(2 \%, 6$ of 259$)$ & \\
\hline Sometimes/often/extremely often & $64(94 \%, 64$ of 68$)$ & $4(6 \%, 4$ of 68$)$ & \\
\hline How often do you limp & & & Odd ratio, $1.0 ; 95 \% \mathrm{CI}, 0.3-4.0 ; \mathrm{p}=1.000$ \\
\hline Never/rarely & $222(97 \%, 222$ of 229$)$ & $7(3 \%, 7$ of 229$)$ & \\
\hline Sometimes/often/extremely often & $94(97 \%, 94$ of 97$)$ & $3(3 \%, 3$ of 97$)$ & \\
\hline
\end{tabular}

$\mathrm{CI}=$ confidence interval.

from commonly used orthopaedic scores, it has not been validated in terms of its repeatability, ceiling effects, and other important parameters. However, we feel the questions selected for this survey are relevant because they were based on prior studies determining factors correlating with patient-perceived symptoms after THA [9, 26, 34, 35]. Fourth, we did not have radiographs available for review to determine if component malposition was present. Thus, it cannot be determined if noise is truly implant-related or originates from the soft tissue. Fifth, we categorized our bearing surfaces as either hard-on-hard or polyethylene for statistical analysis. Thus, we did not report on the impact of individual bearing surface combinations on noise generation and residual symptoms after THA. However, given the overall frequency of noise generation reported, we have concerns that further subdividing our cohorts would limit our ability to find meaningful differences among these bearing surfaces. Lastly, although this study possessed a large sample size, only $60 \%$ of eligible patients completed the survey. Thus, it is possible that our sample may misrepresent those who elected not to participate [12]. Unfortunately, we are not able to comment on the demographics and activity level of those patients who refused to participate because only patients participating in the survey were considered to have consented to the study and have their information collected. We believe our study remains valid because we have achieved a high rate of participation for a telephone survey methodology and believe this information can be generalized to patients with similar demographic variables and activity levels. Furthermore, we have elucidated prosthesis-related factors that may be associated with noise generation. As noted earlier, highvolume, experienced surgeons performed all THAs in this study. Thus, it is possible that the frequency of noise generation and residual symptoms may be even more common in patients undergoing THA by less experienced surgeons.
Overall, 9\% of young patients undergoing THA in this study reported the presence of noise generation. Our reported frequency of noise generation is greater than prior reports specifically focusing only on "squeaking" after CoC THA [1, 30]. Stanat and Capozzi [30], in a metaanalysis of 12 studies assessing outcomes after CoC THA, noted the frequency of squeaking to be $2.4 \%$. However, studies assessing noise generation as a whole (inclusive of squeaking) have reported much higher frequency rates [23, 24]. In a prospective evaluation of $208 \mathrm{CoC}$ THAs, McDonnell et al. [24] noted $11 \%$ to report noises other than squeaking, $8 \%$ irreproducible squeaking, and $13 \%$ reproducible squeaking. Thus, only $69 \%$ of patients were noted to have "silent" hips in this series of patients. However, the clinical significance of noise generation after THA remains unclear.

Female sex was associated with an increased reporting of noise generation. This is in contrast to prior reports in which sex, age, height, and weight were not found to be associated with noise generation [24, 30]. Our study additionally notes primary diagnosis, race, and premorbid UCLA score were not associated with noise generation after THA, factors that have not been previously studied.

We found the use of hard-on-hard bearing surfaces to have an increased likelihood of noise generation versus the use of polyethylene liners (regardless of femoral head material), thus suggesting the bearing surface to be a potential factor associated with noise generation after THA. Patients receiving a CoC or MoM bearing were more likely to report joint noises. With a younger, more active demographic of patients seeking THA, bearing surfaces continue to be modified and developed with the hope of improving prosthesis durability and longevity. At the time THAs were performed during this investigation, MoM and $\mathrm{CoC}$ bearings were thought to have numerous potential advantages versus a traditional, MoP bearing [11, 13, 27, 33]. However, published investigations began to report the 
phenomenon of noise associated with hard-on-hard bearings $[1,2,8,14,24]$. The cause of noise generation in hardon-hard bearings is an area of much debate, because some studies have pointed toward component design [30, 31], others have reported decreased acetabular inclination and anteversion to be risk factors in CoC implants [24], whereas increased acetabular inclination has been noted as a risk factor in MoM implants [4]. Additional potential causes include loss of bearing surface lubrication [7, 32] and femoral component neck geometry [23].

Our study suggests that noise generation is associated with residual symptoms after THA. Among patients with hard-on-hard bearings, noise generation was associated with increased pain and stiffness. Although noise generation was rare in the polyethylene cohort, its presence appears clinically relevant and is associated with increased pain.

It is reasonable to assume patients, unless educated preoperatively, will expect their THA to be quiet and fail to produce noise. Therefore, it is critical that surgeons inform patients preoperatively of the possibility of noise generation after THA. The true etiology of noise generation after THA remains unclear and there is the potential that several factors contribute to noise generation. Future investigations should focus on determining if a causal relationship exists between patient-perceived noise and residual symptoms. Furthermore, prospective, randomized controlled trials may further elucidate whether specific implant designs in THA increase the likelihood of noise generation and residual symptoms. With regard to the specific survey methodology incorporated in this study, future investigations will also be performed to determine its validity in assessing patientperceived outcomes after THA. In conclusion, young patients should be counseled that there is a possibility that they will hear audible noises from their hip, especially if a hard-on-hard bearing is used. Furthermore, surgeons should be aware that noise generation may be associated with a higher degree of symptoms after THA.

Acknowledgments We thank Dr Michael Wallendorf for performing the statistical analyses for this work. We also thank Dr Michael E. Berend, Dr Craig J. Della Valle, Dr C. Anderson Engh Jr, and Dr Javad Parvizi for contributing patients to this investigation.

\section{References}

1. Amanatullah DF, Landa J, Strauss EJ, Garino JP, Kim SH, Di Cesare PE. Comparison of surgical outcomes and implant wear between ceramic-ceramic and ceramic-polyethylene articulations in total hip arthroplasty. J Arthroplasty. 2011;6(Suppl):72-77.

2. Aoude AA, Antoniou J, Epure LM, Huk OL, Zukor DJ, Tanzer M. Midterm outcomes of the recently FDA approved ceramic on ceramic bearing in total hip arthroplasty patients under 65Years of age. J Arthroplasty. 2015;8:1388-1392.
3. Barrack RL, Ruh EL, Berend ME, Della Valle CJ, Engh CA Jr, Parvizi J, Clohisy JC, Nunley RM. Do young, active patients perceive advantages after surface replacement compared to cementless total hip arthroplasty? Clin Orthop Relat Res. 2013;471:3803-3813.

4. Bernasek T, Fisher D, Dalury D, Levering M, Dimitris K. Is metal-on-metal squeaking related to acetabular angle of inclination? Clin Orthop Relat Res. 2011;469:2577-2582.

5. Bourne RB, Chesworth BM, Davis AM, Mahomed NN, Charron KD. Patient satisfaction after total knee arthroplasty: who is satisfied and who is not? Clin Orthop Relat Res. 2010;468:57-63.

6. Bozic KJ, Kurtz S, Lau E, Ong K, Chiu V, Vail TP, Rubash HE, Berry DJ. The epidemiology of bearing surface usage in total hip arthroplasty in the United States. J Bone Joint Surg Am. 2009; 7:1614-1620.

7. Brockett CL, Harper P, Williams S, Isaac GH, Dwyer-Joyce RS, Jin Z, Fisher J. The influence of clearance on friction, lubrication and squeaking in large diameter metal-on-metal hip replacements. J Mater Sci Mater Med. 2008;4:1575-1579.

8. Buttaro MA, Zanotti G, Comba FM, Piccaluga F. Squeaking in a delta ceramic-on-ceramic uncemented total hip arthroplasty. $J$ Arthroplasty. 2012;6:1257-1259.

9. Byrd JW, Jones KS. Prospective analysis of hip arthroscopy with 10-year followup. Clin Orthop Relat Res. 2010;468:741-746.

10. Centers for Disease Control and Prevention (CDC). Prevalence of cholesterol screening and high blood cholesterol among adultsUnited States, 2005, 2007, and 2009. MMWR Morb Mortal Wkly Rep. 2012;61:697-702.

11. Delaunay CP, Bonnomet F, Clavert P, Laffargue P, Migaud H. THA using metal-on-metal articulation in active patients younger than 50 years. Clin Orthop Relat Res. 2008;466:340-346.

12. Fincham JE. Response rates and responsiveness for surveys, standards, and the journal. Am J Pharm Educ. 2008;2:43.

13. Geerdink CH, Grimm B, Ramakrishnan R, Rondhuis J, Verburg AJ, Tonino AJ. Crosslinked polyethylene compared to conventional polyethylene in total hip replacement: pre-clinical evaluation, in-vitro testing and prospective clinical follow-up study. Acta Orthop. 2006;5:719-725.

14. Hamilton WG, McAuley JP, Blumenfeld TJ, Lesko JP, Himden SE, Dennis DA. Midterm results of Delta ceramic-on-ceramic total hip arthroplasty. J Arthroplasty. 2015;30(Suppl):110-115.

15. Hamilton WG, McAuley JP, Dennis DA, Murphy JA, Blumenfeld TJ, Politi J. THA with delta ceramic on ceramic: results of a multicenter investigational device exemption trial. Clin Orthop Relat Res. 2010;468:358-366.

16. Harris WH. Traumatic arthritis of the hip after dislocation and acetabular fractures: Treatment by mold arthroplasty. an endresult study using a new method of result evaluation. J Bone Joint Surg Am. 1969;4:737-755.

17. Kurtz S, Ong K, Lau E, Mowat F, Halpern M. Projections of primary and revision hip and knee arthroplasty in the united states from 2005 to 2030. J Bone Joint Surg Am. 2007;4:780-785.

18. Kurtz SM, Lau E, Ong K, Zhao K, Kelly M, Bozic KJ. Future young patient demand for primary and revision joint replacement: national projections from 2010 to 2030. Clin Orthop Relat Res. 2009;467:2606-2612.

19. Kwon YM, Ostlere SJ, McLardy-Smith P, Athanasou NA, Gill HS, Murray DW. 'Asymptomatic' pseudotumors after metal-onmetal hip resurfacing arthroplasty: prevalence and metal ion study. J Arthroplasty. 2011;4:511-518.

20. Learmonth ID, Young C, Rorabeck C. The operation of the century: total hip replacement. Lancet. 2007;9597:1508-1519.

21. Likert R. A technique for the measurement of attitudes. Arch Psychol. 1932:1-55.

22. Lombardi AV Jr, Berend KR, Seng BE, Clarke IC, Adams JB. Delta ceramic-on-alumina ceramic articulation in primary THA: 
prospective, randomized FDA-IDE study and retrieval analysis. Clin Orthop Relat Res. 2010;468:367-374.

23. Mai K, Verioti C, Ezzet KA, Copp SN, Walker RH, Colwell CW Jr. Incidence of 'squeaking' after ceramic-on-ceramic total hip arthroplasty. Clin Orthop Relat Res. 2010;468:413-417.

24. McDonnell SM, Boyce G, Bare J, Young D, Shimmin AJ. The incidence of noise generation arising from the large-diameter Delta motion ceramic total hip bearing. Bone Joint J. 2013;2:160-165.

25. Nam D, Barrack RL, Potter HG. What are the advantages and disadvantages of imaging modalities to diagnose wear-related corrosion problems? Clin Orthop Relat Res. 2014;472:36653673.

26. Nilsdotter AK, Lohmander LS, Klassbo M, Roos EM. Hip Disability and Osteoarthritis Outcome Score (HOOS)-validity and responsiveness in total hip replacement. BMC Musculoskelet Disord. 2003;4:10.

27. Nizard R, Pourreyron D, Raould A, Hannouche D, Sedel L. Alumina-on-alumina hip arthroplasty in patients younger than 30 years old. Clin Orthop Relat Res. 2008;466:317-323.

28. Radler BT, Ryff CD. Who participates? Accounting for longitudinal retention in the MIDUS national study of health and wellbeing. J Aging Health. 2010;3:307-331.
29. Restrepo C, Post ZD, Kai B, Hozack WJ. The effect of stem design on the prevalence of squeaking following ceramic-onceramic bearing total hip arthroplasty. J Bone Joint Surg Am. 2010;3:550-557.

30. Stanat SJ, Capozzi JD. Squeaking in third- and fourth-generation ceramic-on-ceramic total hip arthroplasty: meta-analysis and systematic review. J Arthroplasty. 2012;3:445-453.

31. Swanson TV, Peterson DJ, Seethala R, Bliss RL, Spellmon CA. Influence of prosthetic design on squeaking after ceramic-on-ceramic total hip arthroplasty. J Arthroplasty. 2010;6(Suppl):36-42.

32. Walter WL, Yeung E, Esposito C. A review of squeaking hips. $J$ Am Acad Orthop Surg. 2010;6:319-326.

33. Willert HG, Buchhorn GH, Fayyazi A, Flury R, Windler M, Koster G, Lohmann CH. Metal-on-metal bearings and hypersensitivity in patients with artificial hip joints. A clinical and histomorphological study. J Bone Joint Surg Am. 2005;1:28-36.

34. Wright JG, Young NL, Waddell JP. The reliability and validity of the self-reported patient-specific index for total hip arthroplasty. $J$ Bone Joint Surg Am. 2000;6:829-837.

35. Zahiri CA, Schmalzried TP, Szuszczewicz ES, Amstutz HC. Assessing activity in joint replacement patients. J Arthroplasty. 1998;8:890-895. 